\title{
Semibatch Emulsion Polymerization of Butyl Acrylate Stabilized by a Polymerizable Surfactant
}

\author{
Chorng-Shyan CHern and Yu-Chang CHEN \\ Department of Chemical Engineering, National Taiwan Institute of Technology, \\ Taipei 106, Taiwan, Republic of China
}

(Received January 17, 1996)

\begin{abstract}
In the semibatch emulsion polymerization of butyl acrylate (BA), the polymerizable surfactant, sodium dodecyl allyl sulfosuccinate (JS-2), increases the particle surface charge density significantly and, thereby, reduces particle size (as small as $90 \mathrm{~nm}$ ) of the latex product. Such a small particle size has not been achieved by means of the surfactant-free technique (normally greater than $300 \mathrm{~nm}$ ). The concentration of JS-2 in the initial reactor charge ([JS-2 $]_{\mathrm{i}}$ ) is the most important parameter in determining the final latex particle size $\left(d_{\mathrm{p}}\right)$. The number of latex particles formed is proportional to [JS-2] $]_{\mathrm{i}}$ to the $0.72-0.80$ power. The experimental data also show that JS-2 should play a similar role in particle nucleation and growth to the conventional surfactant sodium dodecyl sulfate. The saturated particle surface area occupied by one molecule of JS-2 is $0.36 \mathrm{~nm}^{2}$ for the latex prepared by the surfactant-free technique. Furthermore, the saturated particle surface area covered by one molecule of JS-2 increases with particle surface polarity for the JS-2 stabilized latices. The fraction of the chemically incorporated JS-2 buried inside the particles increases with $d_{\mathrm{p}}$.

KEY WORDS Emulsion Polymerization / Polymerizable Surfactant / Semibatch / Latex Particle Size / Butyl Acrylate /
\end{abstract}

Semibatch emulsion polymerization ${ }^{1-13}$ has been widely used in the plant for production of latex products such as adhesives, coatings, thermoplastics, and elastomers. Latex particles are thermodynamically unstable in nature and these particles are generally stabilized by anionic surfactants (e.g., sodium dodecyl sulfate (SDS)). The negatively charged surfactant molecules adsorbed on the particle surface can impart repulsive force among the interactive particles. This action can prevent the interactive particles from flocculating with one another. However, the small, mobile surfactant species can migrate to the surface layer of the polymeric film without any difficulty. Such a phenomenon can have a negative effect on applications such as adhesion of the pressure-sensitive adhesives.

The surfactant migration problem can be eliminated by means of the surfactant-free emulsion polymerization technique. ${ }^{12,13}$ Nevertheless, the latex particles which are stabilized only by the sulfate end-groups $\left(-\mathrm{SO}_{4}^{-}\right)$ derived from the persulfate initiator are relatively unstable because of the very low particle surface charge density. As a result, a significant amount of coagulum forms during the monomer addition period. Limited flocculation often observed in the semibatch surfactantfree emulsion polymerization of butyl acrylate (BA) makes the task of particle size control more difficult. ${ }^{12}$ Both factors cause significant problems in the manufacture of latex products. Incorporation of a small amount of functional monomer (e.g., acrylic acid or methacrylic acid) into the growing polymer particles can greatly improve their stability and, thereby, retard limited flocculation. ${ }^{13}$ However, the particle size of the latex product is still quite large (normally greater than $300 \mathrm{~nm}$ in diameter)

Recently, Urquiola et al. ${ }^{14-16}$ investigated the feasibility of using the polymerizable surfactant, sodium dodecyl allyl sulfosuccinate, in the batch emulsion polymerization of vinyl acetate. It was concluded that final latex particle size decreases with an increase in the concentration of the polymerizable surfactant. The reactions taking place at the latex particle-water interface are very important and the particle size is the key parameter in determining the polymerization rate. However, literature dealing with the semibatch emulsion polymerization system stabilized by a polymerizable surfactant has been nil.

In addition to the surfactant properties (e.g., lowering of surface tension and formation of micelles), the polymerizable surfactant can be chemically incorporated into the emulsion polymer. Thus, immobilized surfactant molecules are incapable of diffusing toward the surface layer of the polymeric film and deteriorating film properties. Furthermore, the sulfonate group $\left(-\mathrm{SO}_{3}^{-}\right)$ covalently coupled to the particle surface can greatly enhance the potential energy barrier against flocculation and, consequently, eliminate limited flocculation during polymerization. Thus, the objective of this project is to study how to use the polymerizable surfactant, sodium dodecyl allyl sulfosuccinate, to prepare poly(butyl acrylate) latices with controlled particle sizes in a semibatch reactor. Another goal of this work is to determine the distribution profile of the covalently bonded surfactant molecules in polymer particles.

\section{EXPERIMENTAL}

\section{Materials}

The chemicals used in this work were butyl acrylate (BA) (Formosa Plastics Co.), sodium dodecyl sulfate (SDS) (Henkel Co.), sodium alkyl allyl sulfosuccinate (Eleminol JS-2) (Sanyo Chemical Industries), sodium persulfate (Riedel-de Haen), nitrogen (Ching-Feng-Harng Co.), and deionized water (Barnsted, Nanopure Ultrapure Water System, specific conductance $<0.057 \mu \mathrm{Scm}^{-1}$ ). The monomer BA was distilled under reduced pressure before use. All other chemicals were used as received. 


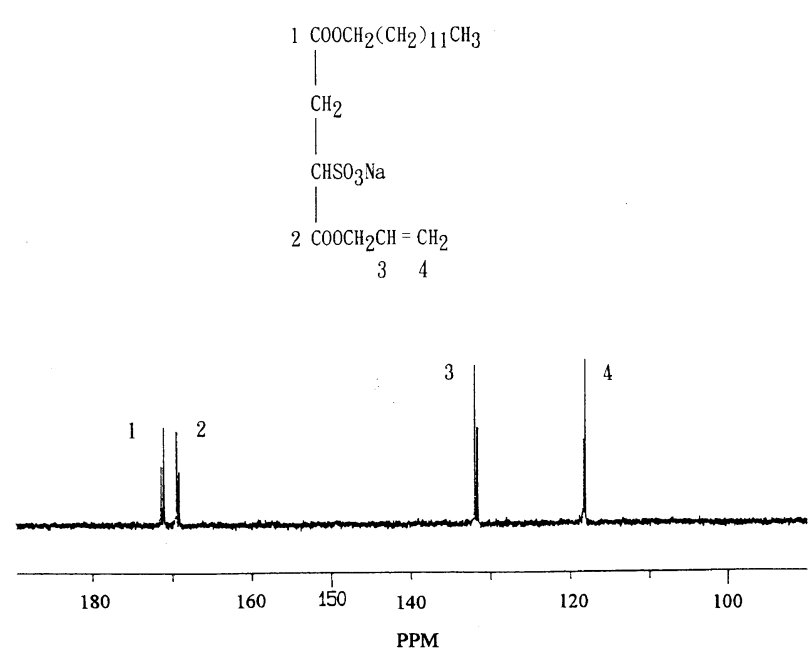

Figure 1. ${ }^{13} \mathrm{C}$ NMR spectra of polymerizable surfactant JS-2.

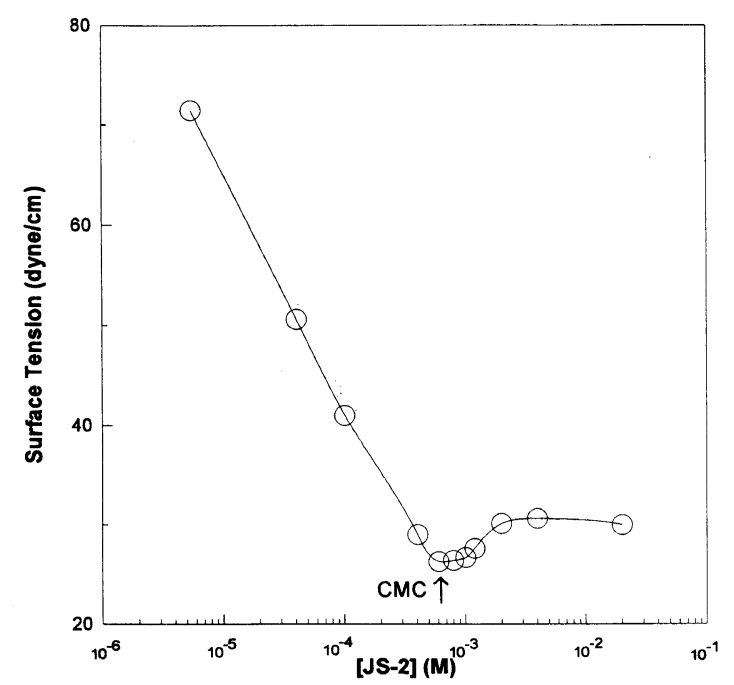

Figure 2. Surface tension as a function of JS-2 concentration in water.

The polymerizable surfactant JS-2 is known to be a $50 / 50$ mixture of the following two isomers:

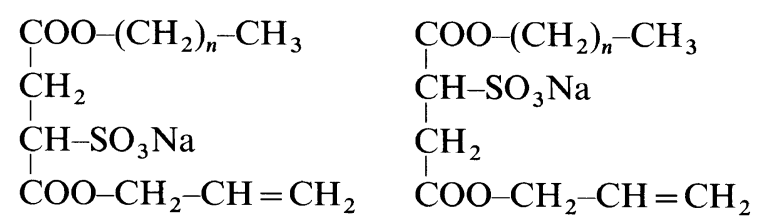

where the value of $n$ is 10.63 according to the elemental analysis method $(52.25 \% \mathrm{C}$ and $8.09 \% \mathrm{H}$ ) (Perkin-Elmer $2400)$. This indicates that the alkyl group shown above $\left(-\left(\mathrm{CH}_{2}\right)_{n}-\mathrm{CH}_{3}\right)$ is dodecyl. The ${ }^{13} \mathrm{C}$ NMR spectra shown in Figure 1 shows that the carbon-carbon double bond corresponding to the peaks at 118 and $132 \mathrm{ppm}$ is present in the JS- 2 molecule. The critical micelle concentration (CMC) of JS-2 in deionized water was determined to be $6.07 \times 10^{-4} \mathrm{M}$ by using a surface tension meter (Face CBVP-A3), as shown by the arrow in Figure 2. The abscissa of Figure 2 ([JS-2]) represents the concentration of JS-2 in water.

\section{Polymerization Process}

Semibatch emulsion polymerization was carried out in a 1-liter glass reactor equipped with a 4-bladed agitator, a thermometer, and a condenser. A typical recipe is
Table I. Typical recipe for semibatch emulsion polymerization of butyl acrylate stabilized by polymerizable surfactant JS-2

\begin{tabular}{lcc}
\hline & Chemicals & Weight/g \\
\hline Monomer emulsion feed & $\mathrm{H}_{2} \mathrm{O}$ & 81.00 \\
& $\mathrm{JS}-2$ & 32.36 \\
& $\mathrm{BA}$ & 294.00 \\
Initial reactor charge & $\mathrm{H}_{2} \mathrm{O}$ & 371.30 \\
& $\mathrm{JS}-2$ & 5.07 \\
& $\mathrm{BA}$ & 17.01 \\
Initiator solution & $\mathrm{H}_{2} \mathrm{O}$ & 15.00 \\
Total weight & $\mathrm{Na}_{2} \mathrm{~S}_{2} \mathrm{O}_{8}$ & 1.56 \\
& & 817.30 \\
\hline
\end{tabular}

Theoretical total solids content $=40 \%$.

Monomer feed rate $=2.26 \mathrm{~g} \mathrm{~min}^{-1}$.

shown in Table I. The polymerization involves addition of water along with initial surfactant and monomer to the reactor at room temperature. The initial reactor charge was purged with nitrogen for $10 \mathrm{~min}$ while the reactor temperature was brought to $80^{\circ} \mathrm{C}$. The reaction was then initiated by adding the initiator solution to the reactor. After $15 \mathrm{~min}$, the monomer emulsion was fed to the reactor over $3 \mathrm{~h}$ by an FMI pump. Polymerization temperature was kept constant $\left(80^{\circ} \mathrm{C}\right)$ throughout the reaction. After monomer emulsion feeding was complete, the reaction system was kept at $80^{\circ} \mathrm{C}$ for $30 \mathrm{~min}$ to reduce the residual monomer to an acceptable level. The theoretical total solid content at the end of polymerization is $40 \%$.

\section{Characterization of Latices}

The finished latex product was filtered through a 40 mesh $(0.42 \mathrm{~mm})$ and a 200 mesh $(0.074 \mathrm{~nm})$ screen in series to collect the coagulum formed during polymerization. Scraps adhering to the agitator, thermometer, and reactor wall were also collected. Total solid content was determined by the gravimetric method. Particle size data were obtained from the dynamic light-scattering method (Otsuka Photal LPA-3000/3100). The soap titration method ${ }^{17-19}$ was used to determine particle surface area covered by one surfactant molecule. Before the start of the soap titration experiment, the latex sample was dialyzed (molecular weight cutoff $=12000-14000$ $\mathrm{g} \mathrm{mol}^{-1}$ ) against deionized water for two days to remove the unreacted surfactant JS-2 and other impurities. The soap titration experiment was conducted at $25^{\circ} \mathrm{C}$ using a $0.01 \mathrm{M}$ solution of JS- 2 . The total solid content of the latex sample was in the range of $0.5-2.5 \%$. The surface tension of the latex sample was measured using a surface tension meter (Face CBVP-A3).

\section{RESULTS AND DISCUSSION}

Two-Level Factorial Design: Control of Particle Size

A two-level factorial design was used to study the effects of three reaction variables on semibatch emulsion polymerization of BA stabilized by the polymerizable surfactant JS-2. These variables include (1) the concentration of JS-2 in the initial reactor charge ([JS-2 $\left.]_{i}\right)$ $(0.005-0.5 \%$ based on total water during the particle nucleation period (i.e., the first $15 \mathrm{~min}$ of the reaction)), (2) concentration of JS-2 in the monomer emulsion feed 
([JS-2 $\left.]_{\mathrm{f}}\right)(2.3-4.5 \%$ based on total monomer in the recipe), and (3) concentration of initiator in the initial reactor charge $\left([\mathrm{I}]_{\mathrm{i}}\right)(0.1-0.4 \%$ based on total water during the particle nucleation period).

To test batch-to-batch variation, one experiment (midpoint) taken from the factorial design (recipe: $[\mathrm{JS}-2]_{\mathrm{i}}=$ $0.2525 \%,[\mathrm{JS}-2]_{\mathrm{f}}=3.15 \%$, and $\left.[\mathrm{I}]_{\mathrm{i}}=0.25 \%\right)$ was carried out twice. Average particle size is $37.8 \pm 0.4 \mathrm{~nm}$ and $100.5 \pm 1.5 \mathrm{~nm}$, respectively, for the latex sample taken immediately before the start of the monomer emulsion feed and the final latex product $\left(d_{\mathrm{p}}\right)$. The reproducibility of the experiment was satisfactory. Furthermore, the overall average amount of coagulum produced in the factorial design is only $0.051 \%$ based on total solid content of the latex product. This indicates that the growing latex particles are relatively stable during polymerization.

The overall average of the final latex particle size $\left(d_{\mathrm{p}}\right)$ in the factorial design is $147.1 \mathrm{~nm}$, which has not been achieved using surfactant-free emulsion polymerization. ${ }^{12,13}$ The standardized effect of each variable $\left([\mathrm{JS}-2]_{\mathrm{i}},[\mathrm{JS}-2]_{\mathrm{f}}\right.$, and $\left.[\mathrm{I}]_{\mathrm{i}}\right)$ on $d_{\mathrm{p}}$ is $-142.3,-26.1$, and $-5.2 \mathrm{~nm}$, respectively. The numerical value (e.g., $-142.3 \mathrm{~nm})$ corresponding to the variable $\left(e . g .,[\mathrm{JS}-2]_{\mathrm{i}}\right)$ represents the standardized effect of the variable on $d_{\mathrm{p}}$ when the variable is changed from the minus ([JS-2 $]_{\mathrm{i}}=$ $0.005 \%)$ to plus level $\left([\mathrm{JS}-2]_{\mathrm{i}}=0.5 \%\right)$. The factorial design shows that the concentration of JS-2 in the initial reactor charge influences the particle size of the latex product the most, followed by the concentration of JS-2 in the monomer emulsion feed. On the other hand, the concentration of initiator in the initial reactor charge shows insignificant effect on $d_{\mathrm{p}}$. The polymerizable surfactant JS-2 in the initial reactor charge is the major latex particle generator. The higher the concentration of JS-2 in the initial reactor charge is, the smaller is the latex particle size at the end of polymerization. On the other hand, the concentration of JS-2 in the monomer emulsion feed does not affect final latex particle size very much and its primary function is to stabilize the growing particles. The addition of JS-2 to the reactor during the monomer emulsion feed might cause secondary nucleation, as shown by its negative standardized effect: $-26.1 \mathrm{~nm}$.

Based on the factorial design, the following predictive equation for $d_{\mathrm{p}}$ was developed for the semibatch emulsion polymerization of BA stabilized by JS- 2 .

$$
\begin{aligned}
d_{\mathrm{p}}(\mathrm{nm})= & 329.2904-909.0620[\mathrm{JS}-2]_{\mathrm{i}} \\
& -30.6895[\mathrm{JS}-2]_{\mathrm{f}}-13.6500[\mathrm{I}]_{\mathrm{i}} \\
& +51.6340[\mathrm{JS}-2]_{\mathrm{i}}[\mathrm{JS}-2]_{\mathrm{f}}-130.7784[\mathrm{JS}-2]_{\mathrm{i}}[\mathrm{I}]_{\mathrm{i}} \\
& +5.7130[\mathrm{JS}-2]_{\mathrm{f}}[\mathrm{I}]_{\mathrm{i}}+951.5901[\mathrm{JS}-2]_{\mathrm{i}}^{2} \\
& +14.2603[\mathrm{JS}-2]_{\mathrm{i}}[\mathrm{JS}-2]_{\mathrm{f}}[\mathrm{I}]_{\mathrm{i}}
\end{aligned}
$$

Figure 3 shows a contour plot of $d_{\mathrm{p}}$ constructed from the predictive equation, in which the parameter $[\mathrm{I}]_{\mathrm{i}}$ is equal to $0.25 \%$. Contour plots at various levels of $[\mathrm{I}]_{\mathrm{i}}$ also show similar trends. In considering the curves with $d_{\mathrm{p}}$ greater than $100 \mathrm{~nm}$, the level of $[\mathrm{JS}-2]_{\mathrm{i}}$ required to maintain the same size decreases gradually with increase in $[\mathrm{JS}-2]_{\mathrm{f}}$. This is because the polymerizable surfactant JS-2 in the initial reactor charge predominates in the particle nucleation process. For very high levels of [JS-

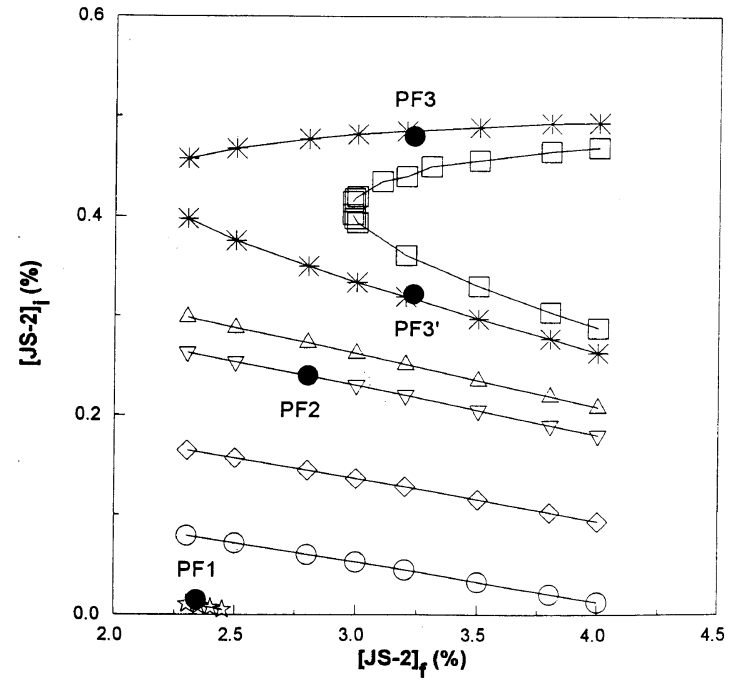

Figure 3. Contour plot of final latex particle size. $[\mathrm{I}]_{\mathrm{i}}=0.25 \%, d_{\mathrm{p}}$ : ( $\square)$ 80; (*) 85; $(\triangle) 100 ;(\nabla) 110 ;(\diamond) 150 ;(\bigcirc) 200 ;(\mathcal{\zeta}) 250 \mathrm{~nm}$.

Table II. Experiments to verify predictive equation of final latex particle size ${ }^{a}$

\begin{tabular}{lcccc}
\hline & PF1 & PF2 & PF3 & PF3 $^{\prime}$ \\
\hline [JS-2 $]_{\mathrm{i}} / \%$ & 0.015 & 0.24 & 0.48 & 0.32 \\
{$[\mathrm{JS}-2]_{\mathrm{f}} / \%$} & 2.34 & 2.80 & 3.23 & 3.23 \\
Prediction $/ \mathrm{nm}$ & 245.4 & 109.8 & 84.2 & 84.2 \\
Experimental & 234.6 & 102.1 & 86.1 & 92.2 \\
Data $/ \mathrm{nm}$ & & & & \\
Error $/ \%$ & 4.4 & 7.1 & 2.3 & 9.5 \\
$d_{w} / d_{n}{ }^{\mathrm{b}}$ & 1.01 & 1.01 & 1.05 & 1.02 \\
\hline
\end{tabular}

${ }^{\mathrm{a}}[\mathrm{I}]_{\mathrm{i}}=0.25 \%$. ${ }^{\mathrm{b}}$ Polydispersity index of particle size distribution.

$2]_{\mathrm{i}}$ and $[\mathrm{JS}-2]_{\mathrm{f}}$ (see top right-hand corner of the contour plot in Figure 3), the level of [JS-2 $]_{\mathrm{f}}$ should increase with $[\mathrm{JS}-2]_{\mathrm{i}}$ in order to maintain the same value of $d_{\mathrm{p}}$. This is probably due to the increasing electrolyte concentration associated with increase in JS-2 loading. Increasing ionic strength can cause a decrease in the potential energy barrier against flocculation among the interactive particles. The resultant limited flocculation may lead to a larger particle size than expected.

Four points in Figure 3 (designated as PF1, PF2, PF3, and $\mathrm{PF}^{\prime}$ ) were then selected to verify the predictive equation for $d_{\mathrm{p}}$. The formulas and experimental data are listed in Table II. Agreement between the experimental data and prediction is reasonably good. The latex product with the particle size being as small as $90 \mathrm{~nm}$ has been achieved. All the final particle size distributions are relatively narrow (see the $d_{w} / d_{n}$ data in Table II) because the residence time distribution for the growing particles in the reactor becomes narrower as polymerization proceeds. Figure 4 shows the number of final latex particles per liter water $\left(N_{\mathrm{p}}\right) v s$. [JS-2 $]_{\mathrm{i}}$ data on a logarithmic scale at three levels of $[\mathrm{JS}-2]_{\mathrm{f}}$, in which the parameter $[\mathrm{I}]_{\mathrm{i}}$ is kept constant at $0.25 \% \cdot \log \left(N_{\mathrm{p}}\right)$-vs.$\log [\mathrm{JS}-2]_{\mathrm{i}}$ profiles for $[\mathrm{I}]_{\mathrm{i}}$ equal to $0.1 \%$ and $0.4 \%$ also show similar trends. It is shown in Figure 4 that at a fixed $[\mathrm{JS}-2]_{\mathrm{f}}$ the number of latex particles increases with [JS-2] $]_{\mathrm{i}}$. The parameter $N_{\mathrm{p}}$ is relatively insensitive to $[\mathrm{JS}-2]_{\mathrm{f}}$ when the parameter $[\mathrm{JS}-2]_{\mathrm{i}}$ is above its CMC. This is because the concentration of JS- 2 in the initial 


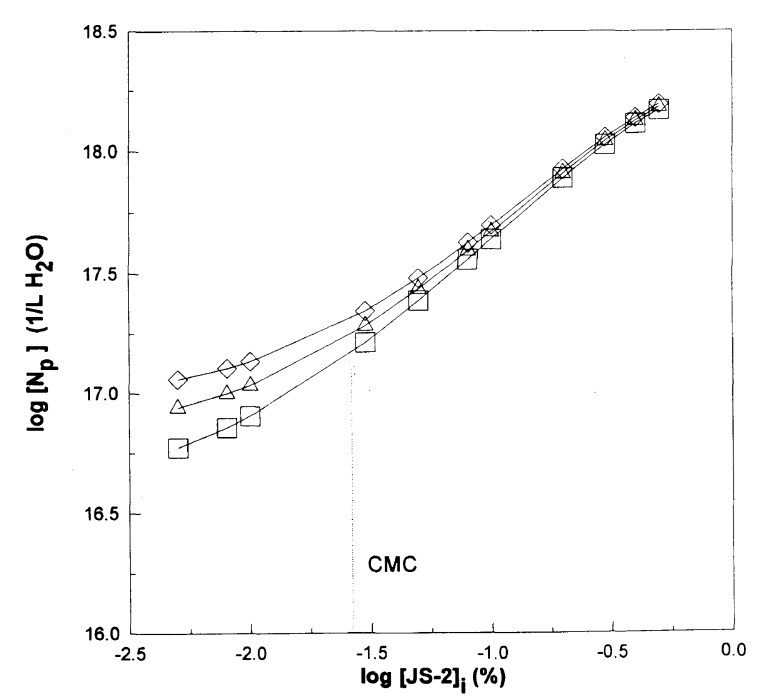

Figure 4. Number of final latex particles per liter water as a function of JS-2 concentration in initial reactor charge. $[\mathrm{I}]_{\mathrm{i}}=0.25 \%$. $[\mathrm{JS}-2]_{\mathrm{f}}$ : ( $\square) 2.30 \% ;(\triangle) 3.15 \% ;(\diamond) 4.00 \%$.

reactor charge is relatively high and it is the predominant factor in determining the number of primary particles nucleated during the very early stage of polymerization. The slope of the least-squares-best-fitted $\log \left(N_{\mathrm{p}}\right)$-vs.$\log [\mathrm{JS}-2]_{\mathrm{i}}$ plot is in the range of $0.72-0.80$ when the parameter $[\mathrm{JS}-2]_{\mathrm{i}}$ is above its CMC. According to the micellar $^{20,21}$ or homogeneous ${ }^{22}$ nucleation mechanism, the slope of the $\log \left(N_{\mathrm{p}}\right)-v s .-\log [\mathrm{S}]$ plot is equal to 0.6 , whereas Feeney et al. $^{23}$ showed that the slope of the $\log \left(N_{\mathrm{p}}\right)-v s .-\log [\mathrm{S}]$ plot should lie between 0.4 and 1.2 . The parameter $[\mathrm{S}]$ represents the concentration of surfactant used in the batch emulsion polymerization system. The experimental data are not conclusive for distinguishing various particle nucleation mechanisms. On the other hand, the parameter $N_{p}$ becomes more dependent on $[\mathrm{JS}-2]_{\mathrm{f}}$ when the parameter $[\mathrm{JS}-2]_{\mathrm{i}}$ is below its CMC. In this case, the addition of JS-2 to the reactor during the monomer emulsion feed results in secondary nucleation because the total particle surface area is not large enough to absorb the primary particles formed in the aqueous phase. As a result, at constant $[\mathrm{JS}-2]_{\mathrm{i}}$ the parameter $N_{\mathrm{p}}$ increases with $[\mathrm{JS}-2]_{\mathrm{f}}$.

\section{Novak Model}

Based on the coagulative nucleation mechanism, ${ }^{24}$ Novak ${ }^{5}$ assumed that latex particle surface is saturated with surfactant and there is no flocculation or secondary nucleation taking place during the monomer feed period. He developed a simple model to describe the particle nucleation and growth processes, as shown in eq 2 .

$$
\log \left(d_{\mathrm{p}}\right)=0.333 \log \left(1 / G_{\mathrm{s}}\right)+0.333 \log (C)
$$

where the parameter $G_{\mathrm{s}}$ is the weight of surfactant used during the particle nucleation period (e.g., $[\mathrm{JS}-2]_{\mathrm{i}}$ in this work). The parameter $C$ is equal to $6 d_{\mathrm{pp}}^{2} G_{\mathrm{p}} /\left(\rho_{\mathrm{p}} A_{\mathrm{m}}^{\prime}\right)$, in which the parameter $d_{\mathrm{pp}}$ is the diameter of primary particles, $G_{\mathrm{p}}$ is the total weight of polymer particles, $\rho_{\mathrm{p}}$ is the density of polymer, and $A_{\mathrm{m}}^{\prime}$ is the particle surface area covered by one gram surfactant. His model predicts that the slope of the $\log \left(d_{\mathrm{p}}\right)-v s .-\log \left(1 / G_{\mathrm{s}}\right)$ plot should be 0.333 .

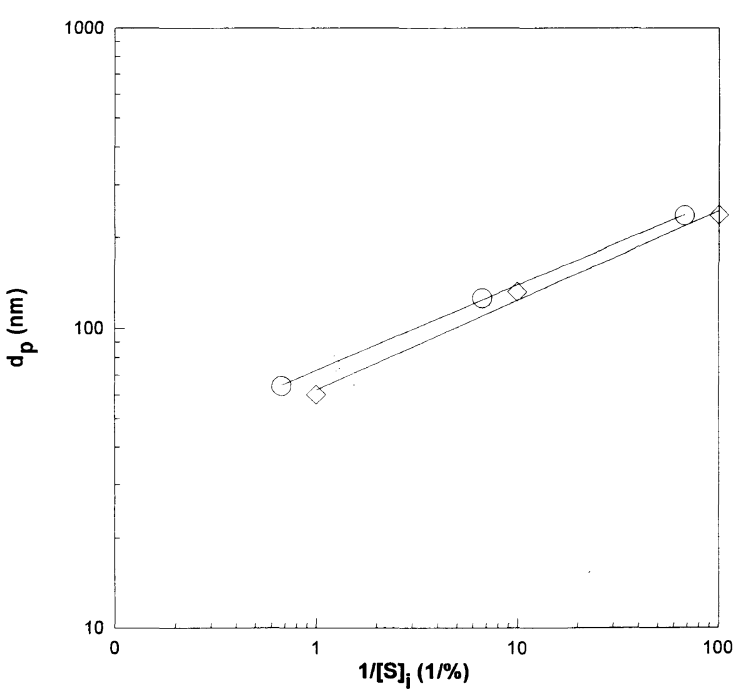

(a)

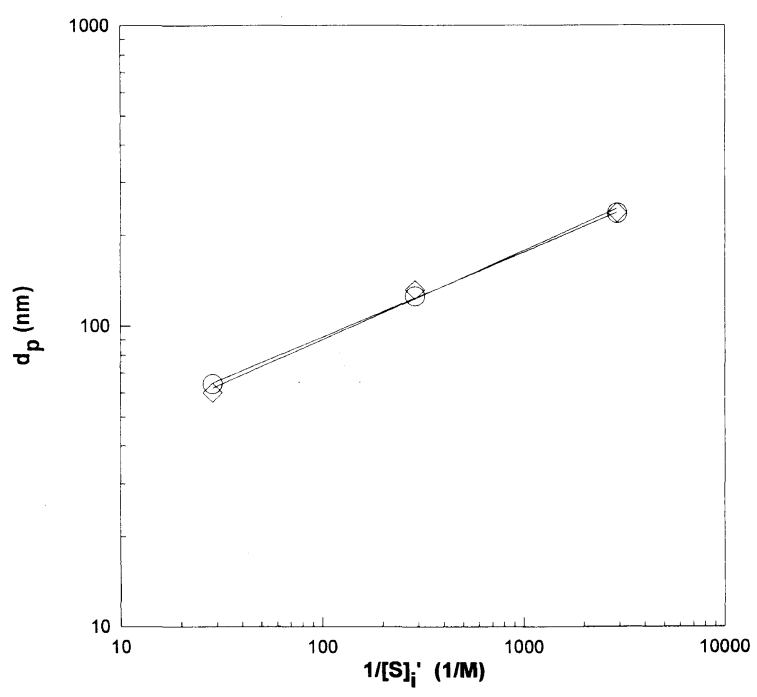

(b)

Figure 5. Final latex particle size $v s$. reciprocal of amount of surfactant in initial reactor charge. (a) $\log \left(d_{\mathrm{p}}\right)-v s \cdot-\log \left(1 /[\mathrm{S}]_{\mathrm{i}}\right)$; (b) $\log \left(d_{\mathrm{p}}\right)-$ vs. $-\log \left(1 /[\mathrm{S}]_{i}^{\prime}\right):(\bigcirc) \mathrm{JS}-2 ;(\diamond)$ SDS.

In this series of experiments, the concentration of surfactant in the monomer emulsion feed and concentration of initiator in the initial reactor charge were kept constant $\left([\mathrm{JS}-2]_{\mathrm{f}}=[\mathrm{SDS}]_{\mathrm{f}}=2.5 \%\right.$ and $\left.[\mathrm{I}]_{\mathrm{i}}=0.25 \%\right)$. Figure 5 a shows final latex particle size $\left(d_{\mathrm{p}}\right)$ vs. the reciprocal of $[\mathrm{S}]_{\mathrm{i}}$ data in logarithmic scale for the polymerizable surfactant JS-2. For comparison, the conventional surfactant SDS was also included in this study. The parameter $[S]_{i}$ represents the concentration of JS-2 or SDS in the initial reactor charge. The slope of the leastsquares-best-fitted straight line is 0.283 and 0.293 for the polymerization system stabilized by JS-2 and SDS, respectively. Both polymerization systems follow the Novak model quite well. In addition, the slope is slightly less than the prediction $(0.333)$, which is probably due to the secondary nucleation taking place in the course of polymerization. The $d_{\mathrm{p}}$ data in Figure $5 \mathrm{a}$ were then replotted against $1 /[\mathrm{S}]_{\mathrm{i}}^{\prime}$ where the parameter $[\mathrm{S}]_{\mathrm{i}}^{\prime}$ has units of $\mathrm{M}$. This was done simply because the molecular weights of JS-2 and SDS were different. Interestingly, this time, both sets of the experimental data almost coincided with each other, as shown in Figure 5b. The 


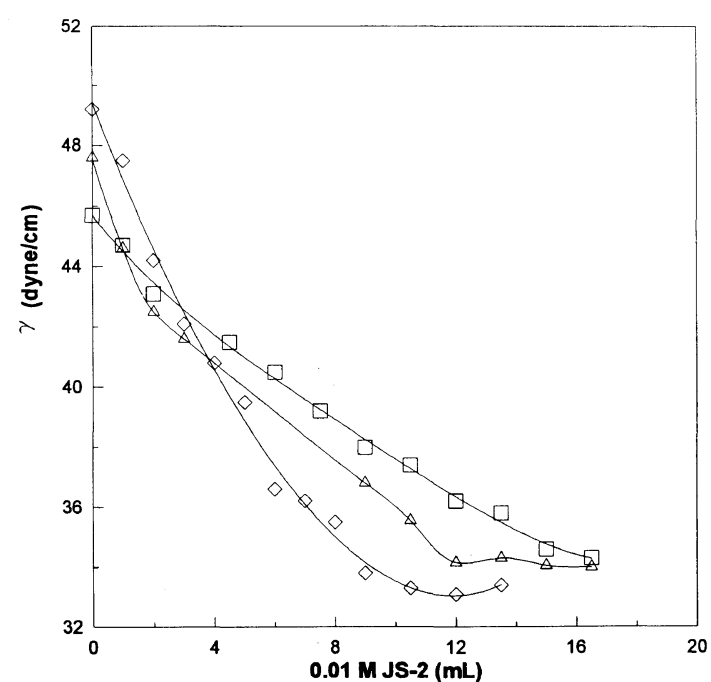

Figure 6. Changes in surface tension with progress of soap titration process for latex PF1. Total solids content: $(\diamond) 0.5 \% ;(\triangle) 1.5 \% ;(\square)$ $2.5 \%$.

polymerizable surfactant JS-2 should thus play a similar role in particle nucleation and growth to the small, mobile surfactant SDS. However, more research is required to verify this postulation.

\section{Soap Titration}

The soap titration method ${ }^{17-19}$ was used to determine the particle surface area covered by one surfactant molecule according to the following equations:

$$
\begin{gathered}
X_{\mathrm{s}} /\left(1-C_{\mathrm{s}}\right)=C_{\mathrm{s}} /\left(1-C_{\mathrm{s}}\right)+\left[E_{\mathrm{s}}-C_{\mathrm{s}} /\left(1-C_{\mathrm{s}}\right)\right] X_{\mathrm{p}} \\
E_{\mathrm{s}}=6 M W_{\mathrm{s}} /\left(d_{\mathrm{p}} \rho_{\mathrm{p}} A_{\mathrm{m}}\right)
\end{gathered}
$$

where the parameter $C_{\mathrm{s}}$ is the weight of surfactant per unit weight of water, $X_{\mathrm{s}}$ is the weight fraction of surfactant in the latex sample, $X_{\mathrm{p}}$ is the weight fraction of polymer particles in the latex sample, $E_{\mathrm{s}}$ is the weight of adsorbed surfactant per unit weight of polymer particles, $M W_{\mathrm{s}}$ is the molecular weight of surfactant, and $A_{\mathrm{m}}$ is the particle surface area covered by one surfactant molecule. Thus, the parameter $A_{\mathrm{m}}$ can be obtained from the slope and intercept of the $X_{\mathrm{s}}-v s .-X_{\mathrm{p}}$ plot at constant surface tension $(\gamma)$ according to eq 3 and 4 .

Three latices PF1, PF3, and PBA were chosen for study. The formulas along with the $d_{\mathrm{p}}$ data for latices PF1 and PF3 can be found in Table II. The latex PBA was prepared by semibatch surfactant-free emulsion polymerization. The particle size of PBA is $532.3 \mathrm{~nm}$. Typical changes in the surface tension $(\gamma)$ with the soap titration process for the latex PF1 at three levels of total solids content $(0.5 \%, 1.5 \%$, and $2.5 \%)$ are illustrated in Figure 6. The soap titration profiles for both latices PF3 and PBA also exhibit similar trends. In general, the surface tension $\gamma$ first decreases rapidly and then levels off as the soap titration proceeds. Figure 7 shows the $X_{\mathrm{s}}-v s .-X_{\mathrm{p}}$ plot at various values of $\gamma$. Based on eq 2 and 3 , the calculated values of $A_{\mathrm{m}}$ as a function of $\gamma$ for latices PF1, PF3, and PBA are compiled in Table III.

As shown in Table III, the parameter $A_{\mathrm{m}}$ first decreases significantly and then levels off with the progress of soap titration. The saturated particle surface area covered by one molecule of JS-2 in the decreasing order

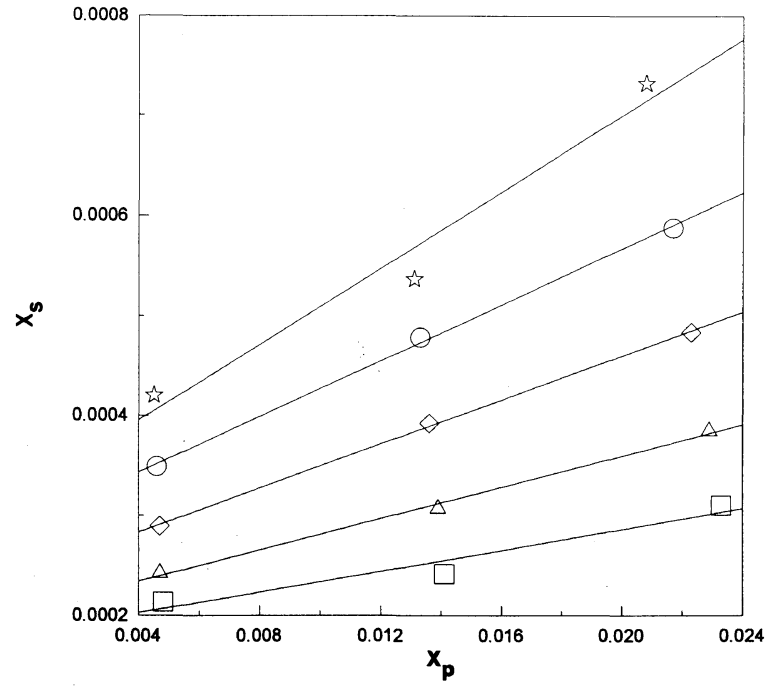

Figure 7. Weight fraction of surfactant in latex sample vs. weight fraction of polymer particles in latex sample for latex PF1. Surface tension: $(\square) 40.0 ;(\triangle) 39.0 ;(\diamond) 37.5 ;(\bigcirc) 36.0 ;(\downarrow)) 34.5 \mathrm{dyn} \mathrm{cm}^{-1}$.

Table III. Calculated particle surface area covered by one molecule of JS-2 as a function of surface tension

\begin{tabular}{|c|c|c|c|c|c|}
\hline \multicolumn{2}{|c|}{ PBA } & \multicolumn{2}{|c|}{ PF 1} & \multicolumn{2}{|c|}{ PF3 } \\
\hline$\gamma$ & $A_{\mathrm{m}}$ & $\gamma$ & $A_{\mathrm{m}}$ & $\gamma$ & $A_{\mathrm{m}}$ \\
\hline dyn $\mathrm{cm}^{-1}$ & $\mathrm{~nm}^{2}$ & dyn $\mathrm{cm}^{-1}$ & $\mathrm{~nm}^{2}$ & dyn $\mathrm{cm}^{-1}$ & $\mathrm{~nm}^{2}$ \\
\hline 46.0 & 4.17 & 40.0 & 3.81 & 42.5 & 7.54 \\
\hline 44.0 & 2.38 & 39.0 & 2.54 & 41.5 & 6.25 \\
\hline 41.0 & 1.30 & 37.5 & 1.80 & 40.0 & 2.69 \\
\hline 38.0 & 0.72 & 36.0 & 1.42 & 38.8 & $2.29^{\mathrm{a}}$ \\
\hline 36.5 & $0.36^{\mathrm{a}}$ & 34.5 & $1.04^{\mathrm{a}}$ & & \\
\hline
\end{tabular}
for latices PF1, PF3, and PBA

${ }^{\text {a }}$ Saturated particle surface area covered by one molecule of JS-2.

is: $\mathrm{PF} 3>\mathrm{PF} 1>\mathrm{PBA}$. This observation is perhaps related to the surface polarity of the polymer particles produced. PF3 polymer particles containing the highest concentration of covalently bonded JS-2 should exhibit the most hydrophilic particle surface (see the recipe in Table II). Thus, the higher the concentration of chemically incorporated JS-2 on the particle surface is, the fewer the JS-2 molecules that can be physically adsorbed on the particle surface in the soap titration experiment. This can lead to the largest saturated particle surface area occupied by one molecule of JS-2 $\left(2.29 \mathrm{~nm}^{2}\right)$ for the latex PF3. On the other hand, the PBA polymer particles stabilized only by the sulfate end-group derived from the persulfate initiator are extremely hydrophobic. Therefore, these PBA particles can physically adsorb a significant number of JS-2 molecules in the soap titration experiment, which can result in the smallest saturated particle surface area covered by one molecule of JS-2 $\left(0.36 \mathrm{~nm}^{2}\right)$. These results are consistent with the work of Paxton $^{18}$ and Ali et al. ${ }^{19}$

The fraction of chemically incorporated JS-2 buried inside the PF1 or PF3 particles can be estimated according to the procedure in the appendix. The estimated fraction of the buried JS-2 is $56 \%$ and $18 \%$ for the latex PF1 $\left(d_{\mathrm{p}}=234.6 \mathrm{~nm}\right)$ and PF3 $\left(d_{\mathrm{p}}=86.1 \mathrm{~nm}\right)$, respectively. This is reasonable because the probability for JS-2 
molecules to be buried inside the particles should be greater for the much larger PF1 polymer particles. This further supports the above finding that the PF1 polymer particles are more hydrophobic than the PF3 polymer particles. Therefore, the saturated particle surface area covered by one molecule of JS- 2 for the PF3 polymer particles is larger than that for the PF1 polymer particles.

Acknowledgment. Financial support from National Science Council, Taiwan, Republic of China (NSC842216-E011-024) is gratefully acknowledged.

\section{APPENDIX}

The following procedure outlines the method of estimating the fraction of the chemically incorporated JS-2 that has been buried inside the PF1 or PF3 polymer particles.

(1) Estimate PBA particle surface area covered by one molecule of sulfate group derived from the persulfate initiator $\left(A_{\text {sulf }}\right)$ according to the following equations.

$$
\begin{gathered}
A_{\text {sulf }}=\left(a_{\mathrm{t}}-a_{\mathrm{ads}}\right) / N_{\text {sulf }} \\
a_{\mathrm{t}}=6 w_{\mathrm{p}} /\left(d_{\mathrm{p}} \rho_{\mathrm{p}}\right) \\
a_{\mathrm{ads}}=\left[\left(w_{\mathrm{s}}-w_{\mathrm{sw}}\right) / M W_{\mathrm{s}}\right] N_{\mathrm{a}} \\
\times\left(0.36 \mathrm{~nm}^{2} \mathrm{~mol}^{-1} \text { for PBA }\right)
\end{gathered}
$$

where the parameter $a_{\mathrm{t}}$ is total particle surface area in the latex sample, $w_{\mathrm{p}}$ is the weight of polymer in the latex sample, $a_{\text {ads }}$ is the particle surface area covered by the adsorbed surfactant (JS-2) at the titration end-point, $w_{\mathbf{s}}$ is the weight of surfactant (JS-2) used at the end-point, $w_{\text {sw }}$ is the weight of surfactant (JS-2) dissolved in water at the end-point that can be determined by the intercept of the $X_{\mathrm{s}}-v s .-X_{\mathrm{p}}$ plot (see eq 3 ), and the parameter $N_{\mathrm{a}}$ is Avogadro's number. The parameter $N_{\text {sulf }}$ in eq A1 is the number of sulfate groups on the particle surface that can be estimated with the knowledge of the amount of initiator used in the polymerization recipe, the initiator decomposition rate constant $\left(1.096 \times 10^{-4} \mathrm{~s}^{-1}\right.$ at $\left.80^{\circ} \mathrm{C}\right)$, the initiator efficiency factor (assumed to be 0.6 in this work), and the reaction time.

(2) Estimate the weight of JS-2 chemically incorporated onto the PF1 or PF3 particle surface during polymerization $\left(w_{\mathrm{chem}}\right)$.

$$
w_{\text {chem }}=\left(a_{\mathrm{t}}-N_{\text {sulf }} A_{\text {sulf }}-a_{\text {ads }}\right) M W_{\mathrm{s}} /\left(0.36 N_{\mathrm{a}}\right)
$$

Note that the parameters $a_{\mathrm{t}}, N_{\text {sulf }}$, and $a_{\text {ads }}$ in eq A4 represent those for the soap titration experiment dealing with the PF1 or PF3 polymer particles in this step.

(3) Estimate the fraction of the chemically incorporated JS-2 buried inside the PF1 or PF3 polymer particles $\left(f_{\text {buried }}\right)$.

$$
\begin{gathered}
w_{\text {buried }}=\left(w_{\text {st }}-w_{\text {chem }}-w_{\text {unreact }}\right) \\
f_{\text {buried }}=w_{\text {buried }} / w_{\text {st }}
\end{gathered}
$$

where $w_{\text {buried }}$ is the weight of the chemically incorporated JS-2 that has been buried inside the PF1 or PF3 polymer particles and $w_{\text {st }}$ is the total weight of JS-2 in the latex sample. The parameter $w_{\text {unreact }}$ in eq A5 is the weight of unreacted JS-2 that can be determined by measuring the surface tension in the dialysate and then performing interpolation of the surfactant concentration by Figure 2.

\section{REFERENCES}

1. P. Fram, G. T. Stewart, and A. J. Szlochtum, Ind. Eng. Chem., 47, 1000 (1955).

2. H. Gerrens, J. Polym. Sci., Part C, 27, 77 (1969).

3. J. Snuparek, Jr., J. Appl. Polym. Sci., 24, 909 (1979).

4. J. Snuparek, Jr. and A. Tutalkova, J. Appl. Polym. Sci., 24, 915 (1979).

5. R. W. Novak, Adv. Org. Coat. Sci. Technol. Ser., 10, 54 (1988).

6. B. Li and B. W. Brooks, Polym. Int., 29, 41 (1992).

7. C. S. Chern and H. Hsu, J. Appl. Polym. Sci., 55, 571 (1995)

8. C. S. Chern, H. Hsu, and F. Y. Lin, J. Appl. Polym. Sci., in press.

9. E. Unzueta and J. Forcada, Polymer, 36, 1045 (1995).

10. E. Unzueta and J. Forcada, Polymer, 36, 4301 (1995).

11. C. S. Chern and F. Y. Lin, J. Macromol. Sci.-Pure Appl. Chem., A33, 1077 (1996).

12. C. S. Chern and C. H. Lin, Polym J., 27, 1094 (1995)

13. C. S. Chern and C. H. Lin, Polym. J., 28, 343 (1996).

14. M. B. Urquiola, V. L. Dimonie, E. D. Sudol, and M. S. El-Aasser, J. Polym. Sci., Polym. Chem. Ed., 30, 2619 (1992).

15. M. B. Urquiola, V. L. Dimonie, E. D. Sudol, and M. S. El-Aasser, J. Polym. Sci., Polym. Chem. Ed., 30, 2631 (1992).

16. M. B. Urquiola, E. D. Sudol, V. L. Dimonie, and M. S. El-Aasser, J. Polym. Sci., Polym. Chem. Ed., 31, 1403 (1993).

17. S. H. Maron, M. E. Elder, and I. N. Ulevitch, J. Colloid Sci., 9, 89 (1954).

18. T. R. Paxton, J. Colloid Interface Sci., 31, 19 (1969).

19. S. I. Ali, J. C. Steach, and R. L. Zollars, Colloids Surf., 26, 1 (1987).

20. W. V. Smith and R. W. Ewart, J. Chem. Phys., 16, 592 (1948).

21. W. V. Smith, J. Am. Chem. Soc., 70, 3695 (1948).

22. C. P. Roe, Ind. Eng. Chem., 60, 20 (1968).

23. P. J. Feeney, D. H. Napper, and R. G. Gilbert, Macromolecules, 17, 2520 (1984).

24. G. Lichti, R. G. Gilbert, and D. H. Napper, J. Polym. Sci., Polym. Chem. Ed., 21, 269 (1983). 